\title{
The segregation of a sand-gravel dam filter of crushed rock and the influence of water content
}

\begin{abstract}
By fulfilling the requirements by modern design criteria, the filter of an embankment dam is typically designed to satisfy strict filtering and drainage properties. Nonetheless, segregation, which develops in homogeneities by separating the coarser fraction from the finer matrix, is by practical experience difficult to avoid. If excessively segregated, the filter becomes inadequate in practice despite fulfilling design criteria. Guidelines indicate that segregation decreases when the soil is wetted, but there is no refined specification to what extent. A simple technique has been developed for lab-testing a filter material's susceptibility to segregate by using an inclined plane sloping onto a horizontal surface at the material's angle of repose. Seven tests of varying water content have been performed on a sand-gravel material sourced from crushed rock. By quantifying segregation by the material's particle size at $15 \%$ passing (i.e., $\mathrm{D}_{15}$ ), and comparing the coarser fraction to the finer, a measure of segregation is proposed, i.e., the segregation ratio, $\mathrm{SR}=\mathrm{D}_{15 \mathrm{C}} / \mathrm{D}_{15 \mathrm{~F}}$. This study shows that dry material segregates excessively $(S R=20)$, when wetted (ca $30 \%$ of optimum water content) there is only some segregation $(\mathrm{SR} \approx 1.5)$, and there is practically no segregation when nearing the optimum water content $(\mathrm{SR} \approx 1.15)$.
\end{abstract}

Volume 4 Issue 6 - 2020

\author{
Hans Rönnqvist,' Romain Girard, Johanna \\ Lundin, ${ }^{3}$ Peter Viklander ${ }^{4}$ \\ 'RQV Teknik AB, Sweden \\ ${ }^{2}$ Golder Associates AB, Sweden \\ ${ }^{3}$ Boliden Mineral AB, Sweden \\ ${ }^{4}$ Luleå University of Technology, Sweden
}

Correspondence: Hans Rönnqvist, RQV Teknik AB, Lindefallet 908, SE-82596 Enånger, Sweden, Tel +46(0)6421787,

Email hans.ronnqvist@rqv.se

Received: October 16, 2020 | Published: November 30, 2020
Abbreviations: $\mathrm{F}_{0.063}$ fines content $(<0.063 \mathrm{~mm})(\%)$; $\mathrm{F}$, mass passing $(\%) ; \varnothing, \quad$ angle of inclined plane of segregation test setup (deg); $\alpha_{\text {ren }}$, angle of repose $(\mathrm{deg}) ; \mathrm{D}_{\mathrm{x}}$, grain size at $\mathrm{x} \%$ mass passing $(\mathrm{mm}) ; \mathrm{D}_{15 \mathrm{C}}$, coarse sample at $15 \%$ passing in segregation test $(\mathrm{mm})$; $\mathrm{D}_{15 \mathrm{~F}}$, fine sample at $15 \%$ passing in segregation test $(\mathrm{mm}) ; \mathrm{SR}=\mathrm{D}_{15 \mathrm{C}}$ $\mathrm{D}_{15 \mathrm{~F}}$, segregation ratio indicating segregation if $>1(\ldots)$; W, water content $(\%) ; \mathrm{w}_{\mathrm{opt}}$, optimum water content $(\%) ; \rho_{\mathrm{s},}$ particle density $\left(\mathrm{g} / \mathrm{cm}^{3}\right) ; \rho_{\text {dry.max }}$, maximum dry density $\left(\mathrm{g} / \mathrm{cm}^{3}\right) ; \mathrm{C}_{\mathrm{u}}$, coefficient of uniformity $\left(\mathrm{C}_{\mathrm{u}}=\mathrm{D}_{60} / \mathrm{D}_{10}\right)(\ldots)$

Nomenclature: fines amount, by weight, of soil finer than $0.063 \mathrm{~mm}$ (European Standard) (\%).

\section{Introduction}

Filters are the most important protection against internal erosion of embankment dams. Given sufficient hydraulic load, inadequate filters may allow unrestricted continuation of internal erosion; a major cause for the failure of embankment dams. ${ }^{1}$ Modern design criteria for filters requires a strict regimen of conditions to be met that includes filtering and drainage requirements. Segregation, on the other hand, is difficult to avoid, and it causes the separation of a material's coarser fraction from its finer, which may turn a filter that fulfill design criteria on paper to a poorly performing filter in practice. Ripley ${ }^{2}$ considered segregation as the "the major culprit to be guarded against," and practical construction experience reveal that segregation becomes nearly inevitable as the range of particle sizes widens, ${ }^{2-4}$ and "almost unavoidable" using cohesionless coarse-grained materials that are dry. ${ }^{5}$ In hydraulic structures such as dams, segregation may create avenues for heavy leakage and forming streaks of soil fines from the core that may be eroded into zones of segregated inadequate filters. ${ }^{3}$ The risk of segregation increases when using poor construction methods and materials vulnerable to segregation..$^{4,6-8}$ However, practical experience and experimental studies show that segregation is generally inhibited when the soil is wetted; ${ }^{4-6}$ furthermore, the "Milligan line", as presented by Milligan ${ }^{5}$ gives a practical delineation between soils that will not segregate when wetted from those that will even when wetted. The material tested herein classify as the former; however, there is no specification as to what water content that constitute wetted. Thus, special emphasis is herein put on the influence of water content on the extent of segregation. The experimental setup using an inclined plane is designed to replicate engineering practice, i.e., downward discharge from the typically specified lift height of dam filter materials sloped at the material's angle of repose, ergo not necessarily worst-case scenario. The material is then sampled in four locations: first pre-test from the homogenized material, then post-test from the segregated zone, if discernible, and lastly from inside the lift at the toe of the inclined plane. An index to indicate segregation is proposed, i.e., the segregation ratio, $\mathrm{SR}$.

\section{Segregation and experimental works by others}

Asmaei et al. $^{7}$ describes segregation as "a localized event that leads to the separation of one type of component or size class from another," and Kenney \& Westland ${ }^{4}$ as the "separation of a graded particulate material into finer and coarser zones." FEMA ${ }^{10}$ defines it as a "tendency of particles of the same size in a given mass of aggregates to gather together." Segregation occurs as described by Asmaei et al. ${ }^{7}$ due to the following main causes: i) kinematic sieving (finer particles separates from coarser particles in motion), ii) inertia/ trajectory (falling particles and gravity effects finer and coarser particles differently), iii) rolling (separation due to a rolling pattern), and iv) impact (finer and coarser particles react differently upon impact). In terms of dam filters and core materials, when segregated, it causes pockets of coarse or fine material, provides the potential for concentrated leakage, and ineffective filters. ${ }^{3,10}$ Examples of field observations are shown in Figure 1A- Figure 1C; i.e., segregation while stockpiling and during transport, and placement, likely the results of poor construction methods. Indeed, conical piles will inherently lead to segregation. ${ }^{10}$ Figure 1D illustrate a forensic photo of a segregated filter in-situ. In existing dams, segregation of filters has been observed in e.g., the Balderhead Dam, Juklavatn Secondary Dam, Churchill Falls Dike, Juktan Dam, Lövön Dam, Tarbela Auxiliary Dam and Wreck Cove Dam, all of which also have experienced poor filter performance. ${ }^{1,2,6,9,11-13}$ To limit the susceptibility to segregation, which typically involves allowing less widely graded soils, the guidelines injects additional constraints on the grading limits. ${ }^{10,14}$ Other 
recommendations, e.g., Sherard et $\mathrm{al}^{15} \&$ Ripley $^{8}$ advise to limit the gravel content (in this case $\mathrm{D} \geq 4.75 \mathrm{~mm}$ ) to $40-60 \%$ in sand-gravel filters, and use uniformly graded soils with $\mathrm{D}_{100} / \mathrm{D}_{10}<6$ (Figure 2). In Milligan $^{5}$ the delineation between soils that will not segregate when wetted from soils that will segregate even when wetted is illustrated by a straight line in a semi-logarithmic gradation plot known as the "Milligan line" (Figure 2). The Milligan line suggest that the soil will not segregate when wetted if on the fine side of the line.

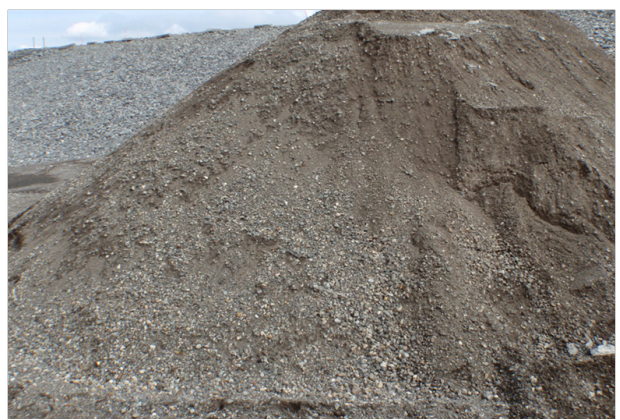

Figure IA Field observation of segregation of stockpiled filter material.

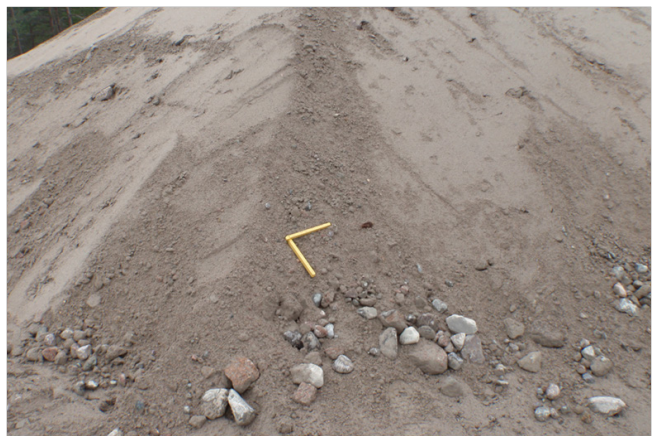

Figure IB Field observation of segregation of stockpiled core material.

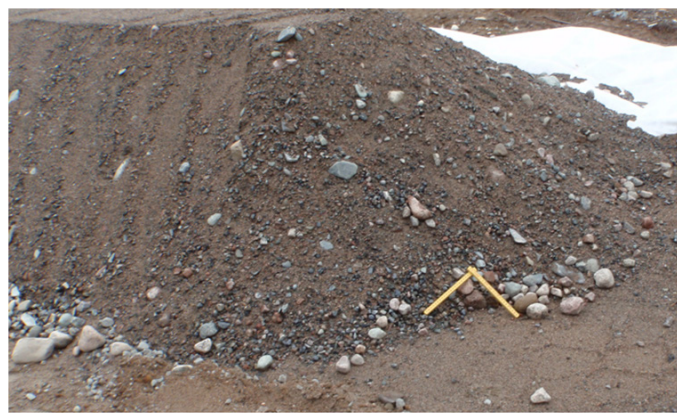

Figure IC Field observation of segregation of placed filter material.

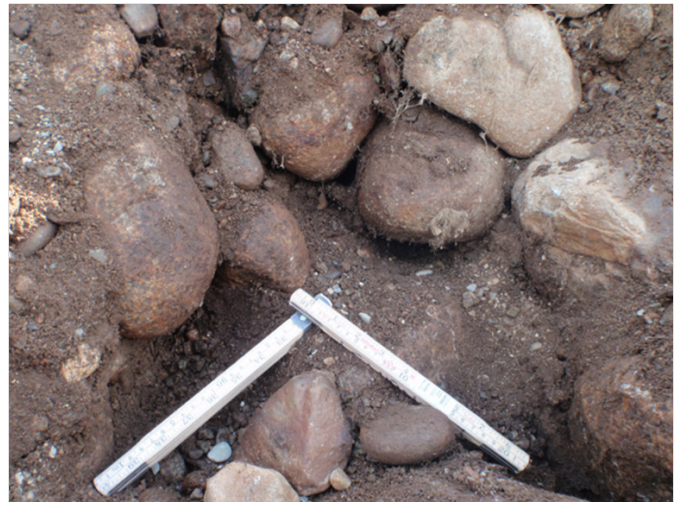

Figure ID Forensic photo of segregated filter material in-situ.

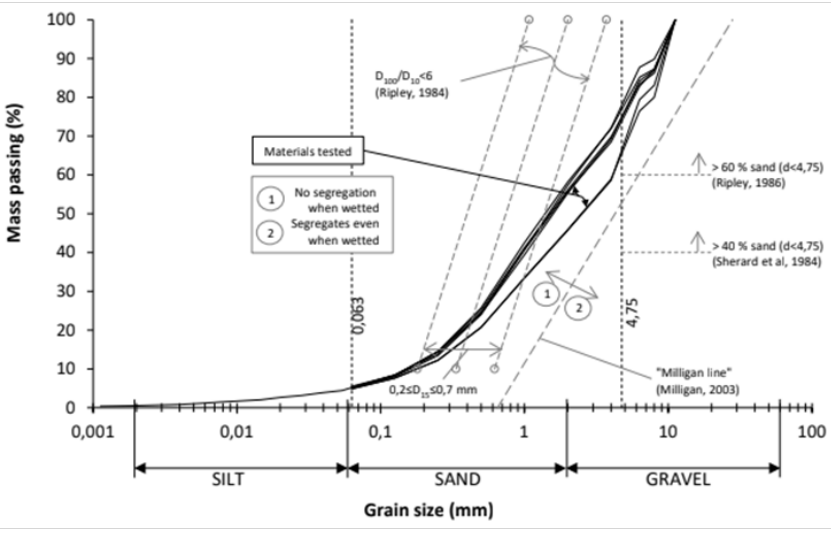

Figure 2 Materials tested and guidelines to limit segregation.

Although somewhat limited, there are experimental studies available in the literature on segregation of dam filter materials ${ }^{4,7,9}$ tested 16 sand-gravel materials in a rotary-drum setup; whereof two gradations that were tested included some fines (D $<0.063 \mathrm{~mm}$ ). Asmaei et al. ${ }^{7}$ used a chute (i.e., inclined surface), $0.6 \mathrm{~m}$ wide and $2.0 \mathrm{~m}$ long, to test 26 sand-gravel gradations without finest. Kenney \& Westland ${ }^{4}$ have shown in tests that insufficient sand to surround coarser particles increases the susceptibility to segregation, particularly if there is less than about $40 \%$ sand $(\mathrm{D}<4.75 \mathrm{~mm}$ ). Furthermore, they showed that water inhibits segregation of sandy soils, which agrees with experimental studies by Sutherland \& Grabinsky ${ }^{9}$ and Asmaei et al. ${ }^{7}$ showed in tests that increase in broadness and curvature is conducive to higher segregation, whereas an increase in granular flow velocity (i.e., the speed at which the soil is dumped) and moisture content inhibit it.

\section{Method and material tested}

A simple laboratory setup was devised composed of an inclined plane sloping into a horizontal surface (Figure 3). The inclined plane forms an angle $\varnothing$ with the $1.0 \mathrm{~m}$ wide and $1.2 \mathrm{~m}$ long horizontal surface. The inclined plane is also $1.0 \mathrm{~m}$ wide. The discharge angle is variable but, in this study, it is set to $40 \mathrm{deg}$. This is the upper limit of the test material's estimated range in angle of repose, $\alpha_{\text {rep }}$, which was roughly determined from a Sand castle test by measuring the slope of the collapsed soil (similar to the technique used by Soroush et al. ${ }^{16}$ The discharge length along the inclined plane is thus $800 \mathrm{~mm}$ given the vertical height of $500 \mathrm{~mm}$, which is intended to replicate current engineering practice of specified lift thickness. Hence typical lifts are in the range of 400 to $500 \mathrm{~mm}$ depending on the filter's location in an embankment. ${ }^{17}$ Thus, compared to the discharge length of Asmaei ${ }^{7}$ the test condition in this study is less severe, and more in line with practice. The test material is subjected to downward discharge onto the inclined plane at the $500 \mathrm{~mm}$ vertical height mark, by a quick motion manually tipping a $10 \mathrm{~L}$ container (weighing about 22 to $23 \mathrm{~kg}$ of material depending on water content) and letting it slide freely to a stop at the horizontal surface allowing it to spread out. Prior to the test, the material is moistened to the intended water content, thoroughly homogenized, and allowed to cure overnight in an airtight container. The material is sampled in four locations: i) pre-test from the homogenized material, and post-test from the segregated ii) coarse and iii) fine zone, and iv) from inside the lift at the toe of the inclined plane. The sampled areas are chosen by visual inspection. Each sample comprised approximately 1 to $2 \mathrm{~kg}$. The material tested is a sand-gravel filter material form crushed $0-8 \mathrm{~mm}$ rock (Figure 2). The coefficient of uniformity, $\mathrm{C}_{\mathrm{u}}=\mathrm{d}_{60} / \mathrm{d}_{10}$, varies between 15 to 26 , 
thus, suggesting a relatively widely graded material. The particle size $\mathrm{D}_{15}$ is between 0.25 to $0.32 \mathrm{~mm}$, fines content on average $5.5 \%$, clay sized particles $<0.002 \mathrm{~mm}$ is $0.5 \%$, and gravel content $(>2 \mathrm{~mm})$ varies between 35 to $55 \%$. The particle density, $\rho_{\mathrm{s}}$, is $3.21 \mathrm{~g} / \mathrm{cm}^{3}$ (determined using ISO, 2015), and the maximum dry density, $\rho_{\text {drymax }}$, is $2.87 \mathrm{~g} / \mathrm{cm}^{3}$ and optimum water content, $\mathrm{w}_{\text {opt }}$ is $4.5 \%$ (determined by Modified Proctor test using ASTM, 2009).

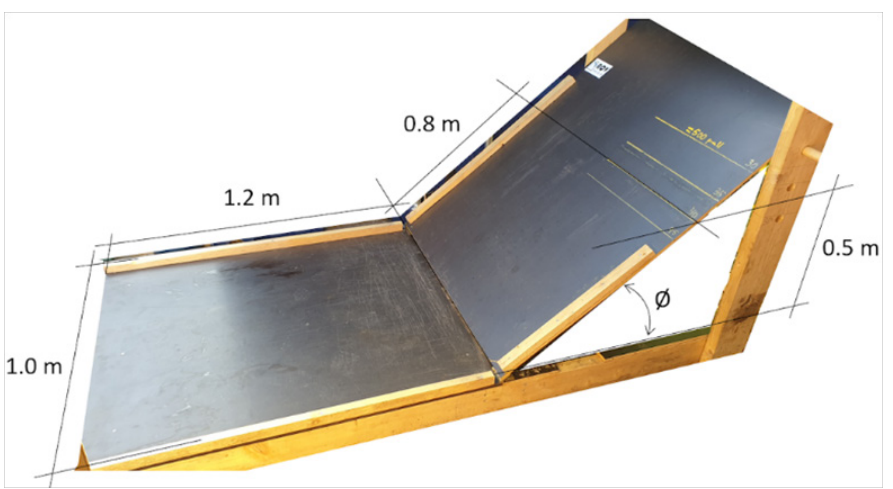

Figure 3 Laboratory setup, inclined plane at an angle.

\section{Results and discussion}

The test material is on the finer side of the "Milligan line", as shown in Figure 2, which by practical experience suggests it will not segregate if wetted. Furthermore, the gravel content (here given for $>4.75 \mathrm{~mm}$ ) varies between 22 to $34 \%$, which satisfies the recommended sand content $(<4.75 \mathrm{~mm})$ of minimum $60 \%$ by Ripley $^{8}$. On the other hand, it is more widely graded than the proposed $\mathrm{D}_{100} / \mathrm{D}_{10}<6$ by Ripley ${ }^{8}$ to obtain an effective segregation resistance. In terms of filtering, the material is within the postulated range $0.2 \leq D_{15}$ $\leq 0.7 \mathrm{~mm} .{ }^{10,18}$ When using filters composed of crushed rock material special considerations apply, e.g., the generation of surplus of fines; nevertheless, Sherard et al. ${ }^{19}$ stipulates from tests that filters composed of crushed rock are as satisfactory as using natural, rounded alluvial soils. Seven tests with varied water content from dry soil to optimum water content have been conducted. Photos from completed tests \#1 and \#2 are shown in Figure 4, the former is the "dry test" Figure 4A and the latter was close to $\mathrm{w}_{\mathrm{opt}}$ Figure 4B. The segregated zones were visually identified (as indicated in Figure 4 by striped lined areas), and the samples were collected in the locations as shown by squares; a procedure that was applied to all tests. Figure 5A- 5G show the particle size distributions of the tested materials sequentially in regards of water content, beginning with the dry and ending with the material near $\mathrm{w}_{\text {opt }}$. By mere visual inspection, it is possible to make out that the segregation gradually reduces with the increase of water content (Figure 5). However, to quantify the degree of segregation, $\mathrm{D}_{15}$ is used in the following. This particle size is closely connected to filter design, filter opening size and permeability ${ }^{6,14,18}$ and for this reason, it is useful to illustrate effects of segregation to the material's $\mathrm{D}_{15}$. By making the comparison between the coarser segregated sample to the finer an index is proposed, i.e., the segregation ratio $S R=D_{15 C} / D_{15 F}$, which at unity $(=1)$ indicates no segregation and $>1$ would indicate segregation. The test conditions and the results are compiled in Table 1, showing the used water content for each test and the respective particle size $\mathrm{D}_{15}$. The results are illustrated in figure 6 , by putting $\mathrm{SR}=\mathrm{D}_{15 \mathrm{C}} / \mathrm{D}_{15 \mathrm{~F}}$ in relation to water content, $\mathrm{w}$, it reveals how the segregation relates to water content. Four levels are proposed: i.e., (1) no segregation when $\mathrm{SR}=1$, (2) Some segregation when $1<\mathrm{SR}<2$, (3) Large segregation when $2 \leq \mathrm{SR}<5$, and (4) Excessive segregation if $\mathrm{SR} \geq 5$. Since $\mathrm{D}_{15 \mathrm{~F}}$ is practically equal to the initial $D_{15}$ (pre-test sample) (Figure 5), some segregation $(\mathrm{SR}<2)$ results in approximately the doubling of the initial $\mathrm{D}_{15}$, which in most cases are still within acceptable bounds in terms of filtering capacity. Large segregation, and certainly in the excessive range, would likely be unacceptable in engineering practice as it will have too much of an adverse effect on the placed material. In a dry state it segregates excessively $(\mathrm{SR}=20)$, as shown in Figure 6 . However, relatively modest water contents (of about $30 \%$ of $\mathrm{w}_{\text {opt }}$ ) generates only some segregation ( $\mathrm{SR} \approx 1.5$ ) suggesting this would constitute "wetted" (or "wet state" as used interchangeably in the literature) since most of the segregation is hereon after inhibited by wetting. Specifically, for the material tested, this corresponds to $\mathrm{w}$ $\approx 1.5 \%$, which, interestingly, agrees with findings of Asmaei et al (2018). Thus, the "Milligan line", proposed by Milligan 5 to which finer materials will not segregate when wetted, is valid for this type of soil. Furthermore, as the water content is nearing the optimum it asymptotically reaches the point of no segregation (indicated in Figure 6 ); indeed, at $\mathrm{w}=4,6 \%$ the segregation is a mere $\mathrm{D}_{15 \mathrm{C}} / \mathrm{D}_{15 \mathrm{~F}} \approx 1.15$. The reason why water reduces segregation in the unsaturated soil is "capillary tensions at points of contact between wetted particles". ${ }_{4}$ In other words, the matric suction, which will develop negative pore pressure helping to hold the particles together by "suction". Thus, the least segregation will occur at the maximum matric suction. Segregation will increase again when the eventual tipping point is reached at excessive water content beyond saturation (also discussed in Asmae et al. ${ }^{7}$

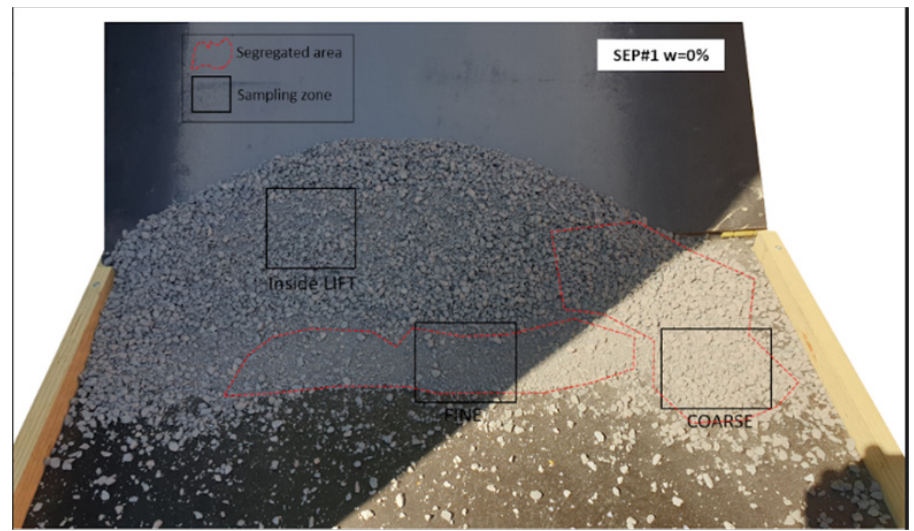

Figure 4A Segregation test Sep\#I at $w=0 \%$.

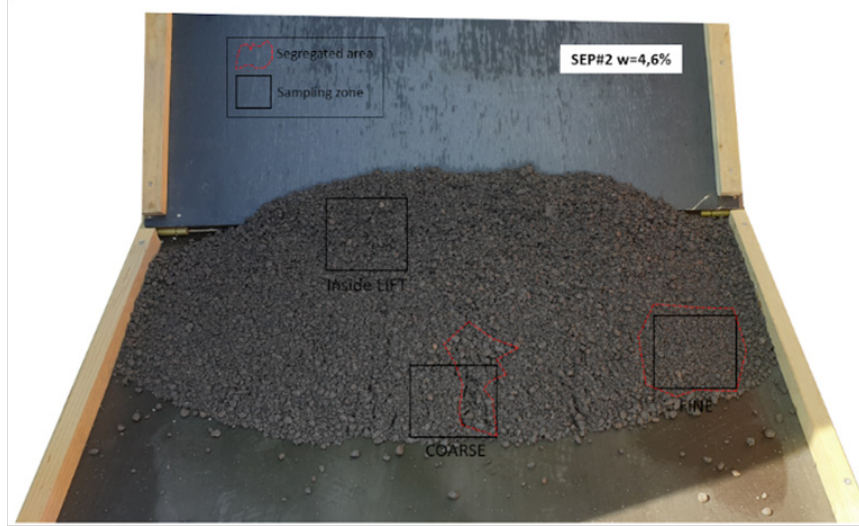

Figure 4B Segregation test Sep \#2 at $w=4,6 \%\left(\approx w_{\text {opt }}\right)$. 
The segregation of a sand-gravel dam filter of crushed rock and the influence of water content

Copyright:

C2020 Rönnqvist et al.

155

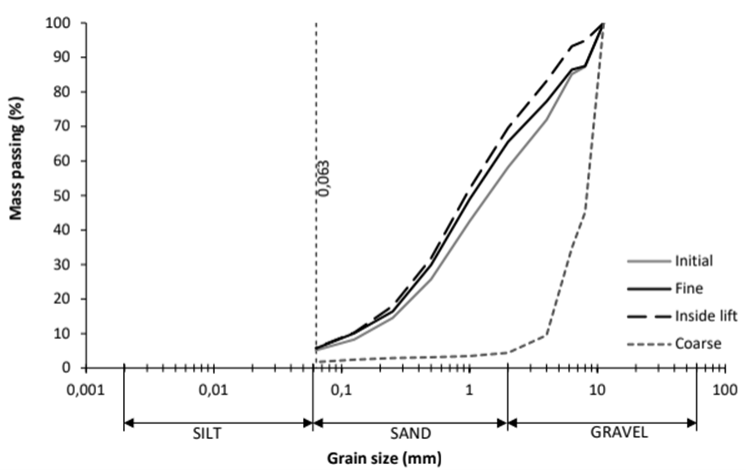

Figure ja

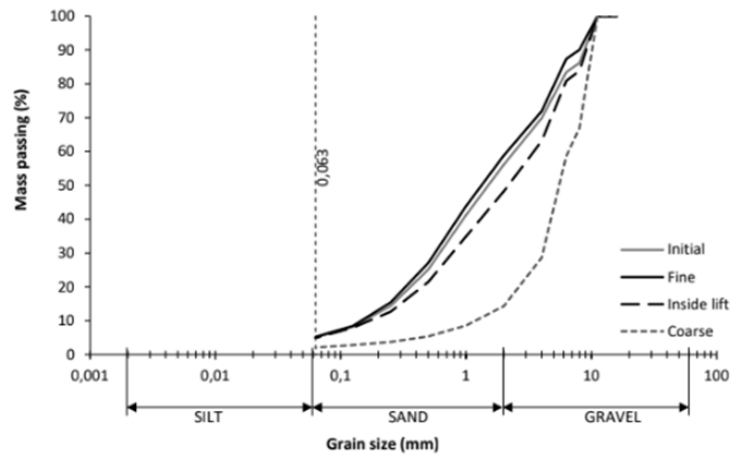

Figure sb

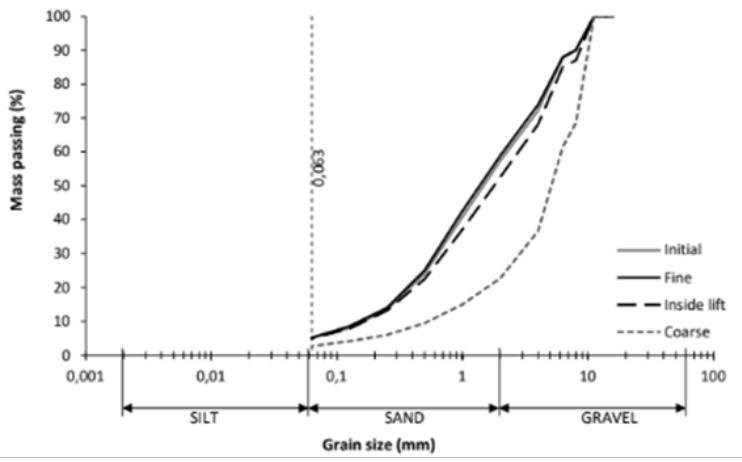

Figure Sc

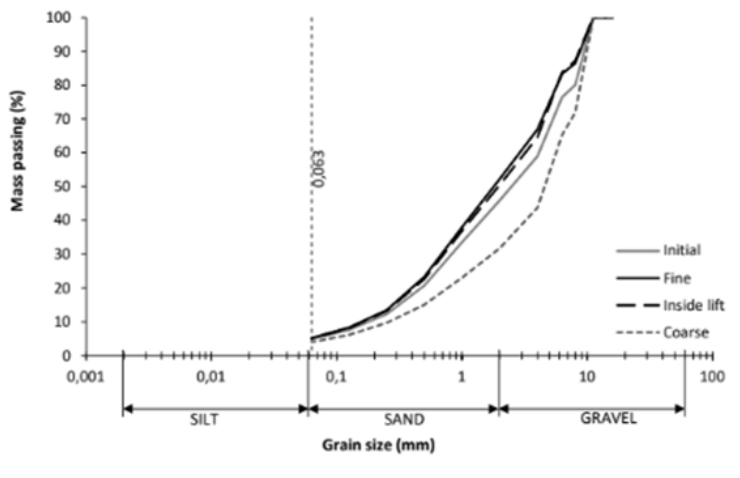

Figure $5 d$

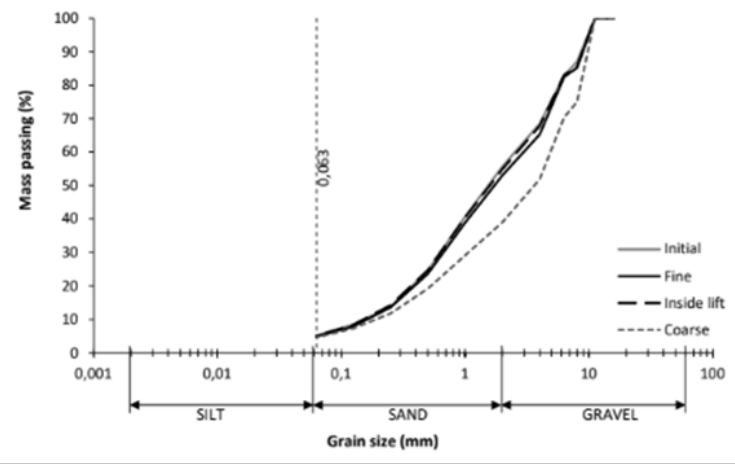

Figure $5 \mathrm{e}$

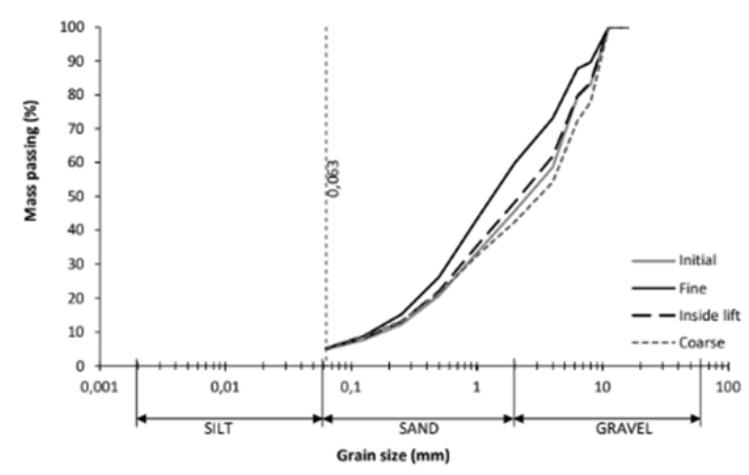

Figure $5 f$

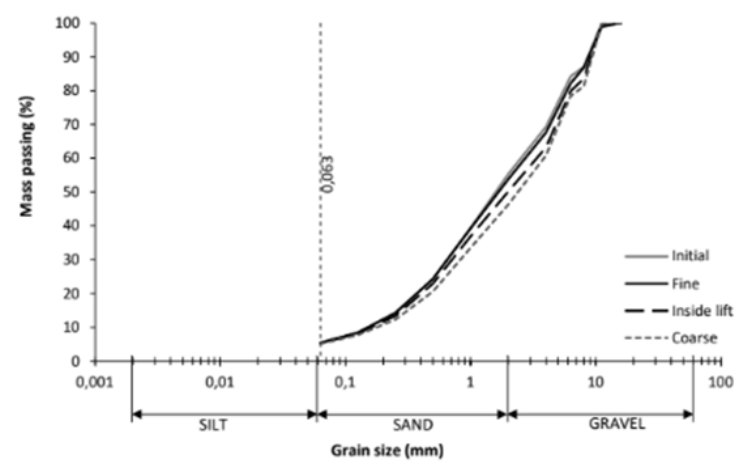

Figure $5 g$

Figure 5 Test results showing particle size distributions at gradually increasing water content A) $0 \%$, B) $0.4 \%$, C) $0.7 \%$, D) $1.1 \%$, E) $2.1 \%$, F) $3.1 \%$ and G) $4.6 \%\left(\approx w_{\text {opt }}\right)$.

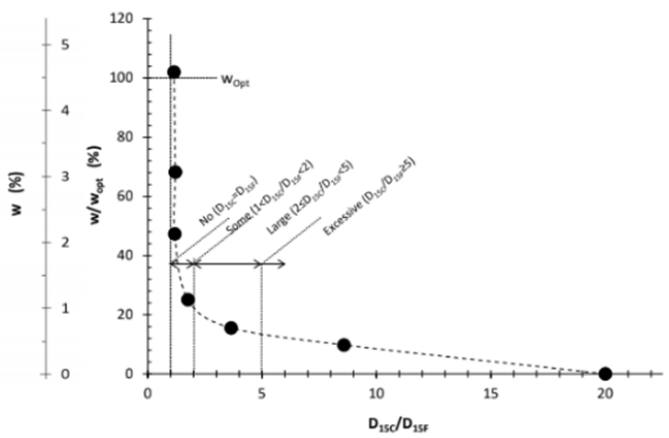

Figure 6 Segregation ratio $S R=D_{15 C} / D_{15 F}$ in relation to water content, $w$.

Citation: Rönnqvist H, Girard R, Lundin J, et al. The segregation of a sand-gravel dam filter of crushed rock and the influence of water content. Material Sci \& Eng. 2020;4(6): I52-I56. DOI: I0.15406/mseij.2020.04.00I43 
Table I Test conditions and results.

\begin{tabular}{llllll}
\hline Test & Water content, $\mathbf{w}, \%$ & Pre-test & $\begin{array}{l}\text { Post-test } \\
\text { Segregation }\end{array}$ & $\begin{array}{l}\text { Satio, SR } \\
\text { res }\end{array}$ \\
\hline Sep\#1 & & $\mathbf{D}_{15}(\mathbf{m m})$ & $\begin{array}{l}\mathbf{D}_{15 F} \text { fine } \\
(\mathbf{m m})\end{array}$ & $\begin{array}{l}\mathbf{D}_{15 c}, \text { coarse } \\
(\mathbf{m m})\end{array}$ & $\mathbf{D}_{15 c} / \mathbf{D}_{15 F}(\ldots)$ \\
Sep\#2 & 0 & 0.25 & 0.22 & 4.4 & 20 \\
Sep\#3 & 4.59 & 0.27 & 0.27 & 0.31 & 1.15 \\
Sep\#4 & 1.13 & 0.32 & 0.29 & 0.5 & 1.75 \\
Sep\#5 & 2.13 & 0.28 & 0.28 & 0.33 & 1.18 \\
Sep\#6 & 3.07 & 0.31 & 0.25 & 0.3 & 1.2 \\
Sep\#7 & 0.44 & 0.26 & 0.25 & 2.1 & 8.57 \\
\hline
\end{tabular}

\section{Conclusions}

The segregation of a sand-gravel filter material from crushed rock is investigated. The test setup replicated not necessarily a worstcase scenario (e.g., end-dumping) but instead an attempt to meet engineering practice. This by using downward discharge at an angle that corresponds to the material's angle of repose and vertical height $500 \mathrm{~mm}$. This would replicate the operation of placing out material in typical lift height allowing any segregation to occur while the soil flows down the lift height to the toe. The main conclusions that can be drawn from the study are:

I. The filter material in a dry state segregates the most, but as the water content increases the segregation is reduced significantly as it nears $\mathrm{w}_{\mathrm{opt}}$; however, acceptable resistance to segregation is achieved at about $30 \%$ of $\mathrm{w}_{\text {opt }}$.

II. The "Milligan line", finer to which a soil will not segregate when wetted, is valid for this type of soil. Tests suggests a minimum of $30 \%$ of $\mathrm{w}_{\text {opt }}$ constitutes "wetted" or "wet state", terms that are used widely but heretofore not sufficiently specified.

III. An index for measuring severity of segregation is proposed, i.e., segregation ratio $\mathrm{SR}=\mathrm{D}_{15 \mathrm{C}} / \mathrm{D}_{15 \mathrm{~F}}$.

IV. To reduce the occurrence of segregation it may be effective to specify strict restraints on the gradation limits. However, using materials that theoretically are less susceptible to segregation does not exclude the importance of applying appropriate construction control and segregation-reducing construction methods.

\section{Acknowledgements}

Gratitude is extended to Boliden for kind permission to publish results from the Aitik filter study. The laboratory testing was performed at RQV Geolab. a subsidiary of RQV Teknik AB.

\section{Conflicts of interest}

The authors declare that there is no conflict of interest.

\section{References}

1. ICOLD. Internal erosion of existing dams, Levees, and dikes, and their foundations, Bulletin 164, International commission on large dams. Paris, France. 2017.

2. Ripley CF. Discussion of: Progress in rockfill dams. J of Geotechn Engr. 1984;114(2):236-240.
3. Leps TM. Sinkholes in dams of coarse broadly graded soils: Discussion, Internation commission on large dams. New Dehli, India. $13^{\text {th }}$ ICOLD Congress; 1979:101-105.

4. Kenney TC, Westland J. Laboratory study of segregation of granular materials, Filters in geotechnical and hydraulic engineering, Balkema, Rotterdam. 1993:313-319.

5. Milligan V. Some uncertainties in embankment dam engineering, $J$ of Geotechn and Geoenv Engr. 2003;129(9):785-797.

6. Foster MA, Fell R. Assessing embankment dam filters that do not satisfy design criteria. J of Geotech and Geoenv Engrg. 2001;127(4):398-407.

7. Asmaei S, Shourijeh P, Binesh S, et al. An experimental parametric study of segregation in cohesionless soils of embankment dams. Geotechn Testing J. 2018;41(3):473-493.

8. Ripley CF. Internal Stability of Granular filters: Discussion, Can Geotech J. 1986;23:255-258.

9. Sutherland K, Grabinsky M. Evaluating segregation in granular filters for earth dams. Canadian Geotechn. Winnipeg. Conference; 144-150.

10. FEMA. Filters for embankment dams - Best practices for design and construction, FEMA Federal emergency management agency; 2011.

11. Foster MA. The probability of failure of embankment dams by internal erosion and piping. New South Wales, Sydney, Australia. The University of New South Wales; 1999.

12. Rönnqvist $H$. Long-term behaviour of internal erosion afflicted dams comprising broadly graded soils. Dam Engineering. 2009;20(2):149197

13. Vaughan PR, Soares F. Design of filters for clay cores of dams. $J$ of Geotechn Engr. 1982;108:17-31.

14. NEH. National Engineering Handbook-Chapter 26 Gradation design of sand and gravel filters, Soil Conservation Service, Oct. 1994.

15. Sherard JL, Dunnigan LP, Talbot JR. Filters for silts and clays. $J$ of Geotech Engr. 1984a;110(6):701-718.

16. Soroush A, Shourijeh PT, Aghajani F, et al. A review of the sand castle test for assessing collapsibility of filters in dams. Geotechn Testing J. 2012;35(4):1-14.

17. Fell R, MacGregor P, Stapledon D, et al. Geotechnical engineering of dams. London, UK. CRC Press; 2017.

18. Sherard JL, Dunnigan LP. Critical filters for impervious soils. $J$ of Geotechn Engr. 1989;115(7):927-947.

19. Sherard JL, Dunnigan LP, Talbot JR. Basic properties of sand and gravel filters. J of Geotech Engr. 1984b;110(6):684-700. 